\title{
Análise Paisagística e de Infraestrutura das Praças do Conjunto Habitacional do Café - Londrina PR
}

Landscape and Infrastructure Analysis of the Squares of the Café Housing Complex Londrina $P R$

Análisis Paisajístico y de Infraestructura de las Plazas del Conjunto Habitacional del Café Londrina $P R$

\section{Alexandro Gasparini Larocca \\ Mestrando, UEM, Brasil alexandrogasparini@yahoo.com.br}

Carolina Cardoso Mestranda, UEM, Brasil. carolinhac.arq@gmail.com

Bruno Luiz Domingos De Angelis Professor Doutor, UEM, Brasil. brucagen@uol.com.br 


\section{RESUMO}

A presente pesquisa tem como objetivo apresentar uma análise das 6 praças que compõe o Conjunto Habitacional do Café em Londrina - Paraná, destacando seus aspectos paisagísticos e sua infraestrutura a fim de compreender a qualidade ambiental desses espaços públicos de infraestrutura urbana. É proposto uma análise dessas praças por fazerem parte de um conjunto habitacional em que o traçado do bairro incluiu no total seis praças internas, dando uma nova identidade ao traçado urbano do bairro. Para a análise foi realizado trabalho de campo com base em dois formulários, baseados na metologia desenvolvida por De Angelis, Castro e De Angelis Neto (2004) em que propõe critérios para análise das condições de vegetação e infraestrutura das praças. O primeiro formulário consiste na avaliação quantitativa e qualitativa da infraestrutura e vegetação existente no local. O segundo formulário tem o objetivo de fazer o levantamento dos aspectos quantitativos da vegetação existente nas seis praças. Os resultados obtidos na pesquisa proporcionam o conhecimento da real situação desses espaços, sendo os equipamentos avaliados estão em boas condições de uso e a vegetação existente no local não apresentam sinais de doenças.

PALAVRAS-CHAVE: Espaço Livres, cidades, meio ambiente.

The present research aims to present an analysis of the 6 squares that make up the Coffee Housing Complex in Londrina - Paraná, highlighting its landscape aspects and its infrastructure in order to understand the environmental quality of these public spaces of urban infrastructure. It is proposed an analysis of these squares for being part of a housing complex in which the layout of the neighborhood included a total of six internal squares, giving a new identity to the urban layout of the neighborhood. For the analysis, fieldwork was carried out based on two forms, based on the methodology developed by De Angelis, Castro and De Angelis Neto (2004), which proposes criteria for analysis of the vegetation conditions and infrastructure of the squares. The first form consists of the quantitative and qualitative evaluation of the existing infrastructure and vegetation. The second form has the objective of surveying the quantitative aspects of the existing vegetation in the six squares. The results obtained in the research provide the knowledge of the real situation of these spaces, being the equipments evaluated are in good conditions of use and the existing vegetation in the place do not show signs of diseases.

\section{KEYWORDS: Free Spaces, Cities, Environments}

El presente estudio tiene como objetivo presentar una evaluación de las seis áreas que componen el Conjunto Habitacional del Café en Londrina - Paraná, destacando sus paisajes y su infraestructura en el sector de la calidad ambiental en los espacios públicos de infraestructura urbana. Ésta es una propuesta que se basa en la construcción de un conjunto de viviendas unifamiliares en el que el trabajo del barrio no incluye un total de seis oficinas internas, lo que da una nueva identidad al trabajo urbano del barrio. Para un análisis de los trabajos realizados con base en dos formuladores, se basó en la metodología desarrollada por De Angelis, Castro y De Angelis Neto (2004). El primer tipo consiste en la evaluación cuantitativa y cualitativa de la infraestructura y la vegetación existente no local. O segundo formar el objetivo de realizar el levantamiento de los dos cuantitativos de la vegetación existente en las seis prácticas. Los resultados obtidos en la investigación se corresponden con el conocimiento de la realidad de los espacios, los equipos se encuentran en buenas condiciones de uso y la vegetación no existe no local.

PALABRAS CLAVE: Espacio Libres, ciudades, medio ambiente. 


\section{INTRODUÇÃO}

As pessoas coexistem em sociedade com outros seres humanos por meio do ambiente em que estão inseridas. Além disso, a cidade interage com os diversos grupos que fazem parte de sua paisagem, onde o indivíduo estrutura os elementos e organiza as formas urbanas, que, por meio de ligações sociais, constroem seus espaços de vivência urbana.

De acordo com De Angelis et al (2004) durante a história da humanidade a praça é o espaço onde importantes fatos ocorreram. Entre esses fatos é possível destacar: na Ágora, onde Sócrates foi colocado sob processo; O Império homônimo nasceu no Fórum de Roma; o berço da Revolução Comunista aconteceu na Praça de São Petersburgo e a Plaza de Mayo em Buenos Aires surgiu o movimento das mães que procuram seus filhos que despareceram durante o regime militar.

A sociedade tem atribuído diversos aspectos às praças ao longo do tempo, sendo que, conforme Yokoo e Chies (2009) no momento da organização dos espaços e no planejamento da estrutura urbana, as praças podem ser classificadas como verdadeiros elos entre os diversos espaços criados, de modo que, estas tenham a conotação de espaços, ocorrendo a vivência de várias etapas da vida do ser humano.

Assim, o objetivo deste artigo é analisar o paisagismo e a infraestrutura das seis praças que fazem parte do Residencial do Café, bairro localizado na cidade de Londrina - Paraná. Por meio dessa análise é possível identificar a qualidade ambiental desses espaços públicos e a infraestrutura instalada nas praças.

O método utilizado é a metodologia desenvolvida por De Angelis et al (2004) que propõe critérios para análise das condições de vegetação e infraestrutura das praças. A análise é desenvolvida por meio de dois formulários: O primeiro consiste na avaliação quantitativa e qualitativa da vegetação existente, e o segundo formulário tem como função auxiliar no levantamento quantitativo e qualitativo da estrutura existente nas praças. Após a aquisição das informações elaborou-se o diagnóstico das praças e em seguida as conclusões sobre as análises realizadas. 


\section{MÉTODO}

Para a análise do objeto de estudo, foi utilizado a Metodologia para levantamento, cadastramento, diagnóstico e avaliação das praças no Brasil, desenvolvida por De Angelis, Castro e De Angelis Neto (2004), onde são utilizados dois formulários principais para a análise das praças. O primeiro visa a avaliação do mobiliário existente em cada praça, dividido em duas fichas para avaliação: a primeira ficha é utilizada para quantificar os equipamentos e estruturas das praças analisadas, visando o levantamento da existência ou não de determinados mobiliário e estruturas, bem como, determinar os materiais que foram utilizados em sua confecção; outra informação pertinente que deve ser anotada na ficha é a forma geométrica da praça; a segunda ficha aplicada para avaliar qualitativamente essas estruturas, conservação dos equipamentos, sendo os objetos listados na primeira ficha, avaliados por meio de conceitos - péssimo, ruim, regular, bom e ótimo - correspondendo as notas que variam conforme a escala de 0,0 a 0,5péssimo; 0,5 -I 1,5-ruim; 1,5 -I 2,5-I regular; 2,5-I 3,5-bom; 3,5-4,0-ótimo.

Além disto, a metodologia estabelece parâmetros rígidos para nortear o trabalho e não interferir na avaliação dos equipamentos, conforme segue:

1- Bancos: estado de conservação; material utilizado; conforto; localização nos caminhos; recuados ou não; se em áreas sombreadas ou não; desenho; quantidade; distanciamento.

2- Iluminação: alta ou baixa - em função da copa das árvores; tipo (poste, super poste, baliza, holofote); quantidade; localização; funcionalidade; material empregado; conservação; distanciamento.

3- Lixeiras: tipo; quantidade; localização; funcionalidade; material; conservação; distanciamento.

4- Sanitários: condições de uso; conservação; quantidade.

5- Telefone Público: localização (se na praça, próximo ou distante); conservação).

6- Bebedouros: tipo; quantidade; condições de uso; conservação.

7- Piso: material empregado; funcionalidade; conservação.

8- Traçado dos caminhos: funcionalidade; largura; manutenção; desenho.

9- Palco/Coreto: funcionalidade; conservação; design; uso; se compatível com o desenho da praça.

10- Obra de Arte: significância da obra de arte; conservação; inserção na praça.

11- Espelho d'água/chafariz: em funcionamento; se inserido no contexto da praça; conservação.

12- Estacionamento: conservação; sombreamento; segurança.

13- Taxi e Ônibus: localização; possui abrigo; conservação.

14- Quadra esportiva: quantidade; conservação; material empregado; iluminação; cercada.

15- Equipamentos para exercícios físicos: tipo e quantidade; material; conservação. 
16- Estrutura para terceira idade: quais existem; conservação.

17- Parque Infantil: brinquedos que compõem; material e cor; área reservada e protegida; conservação.

18- Banca de Revista: localização (periférica, central, evidência ou não); material; design; estética (compatível com a praça).

19- Quiosque para alimentação: tipo; higiene; estética; localização.

20- Conservação: estado geral da praça (equipamentos, estruturas, varrição, limpeza).

21- Localização: próximo ou distante de centros habitados.

22- Vegetação: estado geral; manutenção.

23- Paisagismo: escolha e locação das espécies; criatividade; inserção do verde.

24- Conforto ambiental: presença de agentes que causam poluição sonora; localização; trânsito de veículos; relação entre área sombreada e não; impermeabilização da área da praça e entorno; caracterização visual da praça e entorno.

Na segunda etapa da análise, é utilizada uma segunda ficha na qual é inserido os dados relativos à vegetação da praça. $O$ levantamento quantitativo da vegetação deve ser realizado por meio da contagem das espécies arbóreas e de palmáceas, a vegetação arbustiva e herbácea. Além disso, foram classificados de acordo com o gênero e espécie os diferentes grupos de vegetais e sua família botânica.

\section{A PRAÇA NA CIDADE}

A sociedade, que está em constante transformação, tem atribuído novas características às áreas de uso públicas urbanas ao longo de sua história. De acordo com Saldanha (2011) na antiguidade a ágora era o principal espaço das cidades gregas, em que os cidadãos utilizavam para exercer atividades comerciais, políticas religiosas e culturais. Segundo Silva et al (2011) a partir do momento que surgiu a necessidade de espaços que abrigassem os encontros, festividades e as atividades de trocas, as praças começaram a ser inseridas na urbe, e com sua evolução no tempo passaram a ser áreas centrais urbanas.

$\mathrm{Na}$ definição de Saldanha (1993), a praça é um espaço privilegiado nas suas diferentes perspectivas e não pode ser concebida apenas na sua dimensão física, em sua forma, pois seu significado é social. Desde cedo aprendemos que as praças são locais de brincadeiras e convivência, sendo que essa característica da praça sempre esteve presente ao longo da história das cidades e que Lefebvre (1991) chama de espaço vivido, espaço da vida onde a vida acontece. No Brasil, de acordo com Andrade e Bovo (2010) as primeiras praças surgiram em frente às igrejas. Marx (1980) acrescenta que muitas vezes este local é confundido com jardins, servindo para reunião de pessoas e para o exercício de várias atividades, surgindo diante das capelas e igrejas, tendo destaque na paisagem urbana. E diferente das praças medievais, segundo Robba e Macedo (2003) nas praças brasileiras aconteciam todas as atividades ao mesmo tempo, 
funcionando como um espaço polivalente, local de manifestações de diversos costumes e hábitos da população.

Já a praça contemporânea é vista como um espaço que não tem função específica e também não depende exclusivamente de um edifício ou algum monumento, conforme afirma Favole (1995) sua principal função é de ser um local atrativo de encontro e de reunião. Lamas (1993) acrescenta que a praça é um espaço de encontro, de permanência, práticas sociais, manifestações da vida urbana e comunitária. Para Font (2003) entende-se a praça como um espaço de reuniões, construído para a sociedade, ponto de partida e de chegada, concentração e dispersão, local que abriga, dentro ou fora, o comércio, podendo ser forma e informal.

Ainda sobre o contexto das praças, Macedo e Robba (2003) afirmam que a praça, que possui um cenário ajardinado, tem como objetivo o lazer, a reflexão, o entretenimento, convivência da população, valorizando o uso da vegetação na cidade, como meio de diminuir os efeitos da urbanização nos grandes centros urbanos.

Os espaços livres urbanos, como praças e parques, tem grande importância na qualidade ambiental e na vida da população, pois conforme afirma Silveira e Barros (2001), a vegetação existente nos espaços ajardinados são componentes importantes na paisagem urbana. Sendo que o contato da natureza age no ser humano como um meio de proporcionar relaxamento.

Porém, com as novas possibilidades de lazer e o surgimento de tecnologias, conforme Bovo e Andrade (2012) as praças públicas tornaram-se locais vazios, já que as cidades não conseguem garantir segurança a população. Em grandes centros urbanos, são encontradas facilmente, praças abandonadas e pouco frequentada devido à falta de estrutura adequada e segurança.

Segundo Meneguetti (2005) a apropriação dos espaços faz parte das condições necessárias para criar lugares e identificação das pessoas com a cidade. Nesse contexto é possível observar que foram várias as mudanças pelas quais as praças passaram ao longo da história. São modificações que não estão esgotadas e cada vez estão sendo reelaboradas no que diz respeito a sua definição, concepção, aos aspectos físicos e formas de uso.

\section{RESULTADOS E DISCUSSÃO}

Neste capítulo serão apresentados os resultados obtidos com a aplicação da metodologia de avaliação e diagnóstico das praças brasileiras. As informações foram sintetizadas, pois as praças analisadas apresentam um padrão quanto a forma e seus equipamentos. $O$ município de Londrina está localizado no norte do Estado do Paraná, sendo que sua área urbana é de 245,02 km². A cidade começou a ser construída em 1929 pela Companhia de Terras Norte do Paraná (CTNP) sendo emancipada em 12 de dezembro de 1934. O desenvolvimento da cidade foi rápido, principalmente por causa da expansão da cafeicultura. Já na década de 1970 a cidade teve um aumento populacional intenso, de forma que o crescimento urbano ficou prejudicado pela falta de planejamento da ocupação urbana, já que a cidade foi inicialmente projetada para abrigar 30.000 habitantes. Nas décadas seguintes a urbe atraiu ainda mais moradores que estavam buscando melhorias na área profissional, negócios e em atividades sociais (LONDRINA, 
2017). Conforme informações do IBGE (2017) Londrina tem 558.439 habitantes. Segundo Ayoub (2014) o Conjunto Residencial do Café, onde estão localizadas as praças analisadas, está localizado na zona leste da cidade de Londrina e foi implantado no ano de 1969 pela empresa Inocoop.

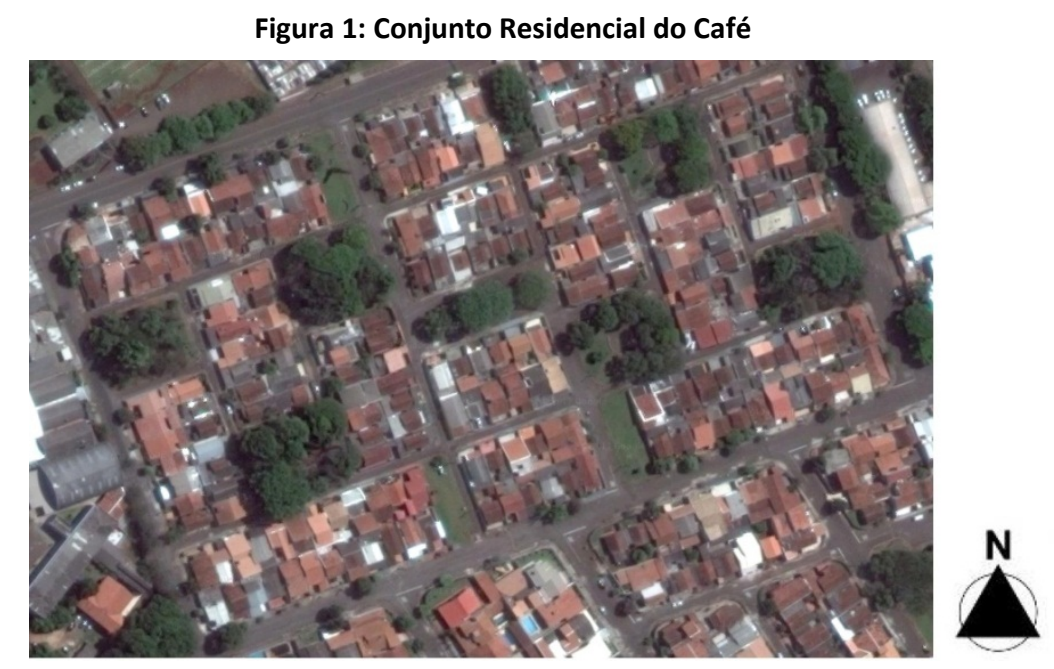

Fonte: Google Maps, 2017.

O projeto do Residencial do Café se destaca dos demais loteamentos pela existência de seis praças internas no bairro. Segunda Ayoub (2014) o traçado das quadras são retilíneos, sendo que as quadras internas são de tamanho reduzido devido à presença das praças retangulares distribuídas de forma homogênea em toda área do bairro. Todas as praças possuem área de $900 \mathrm{~m}^{2}$ e o terreno é plano. $O$ acesso ao bairro e as praças é reservado sendo somente aos moradores pelo fato das vias terem apenas 3 metros de largura. 


\section{Revista Nacional de}

Figura 2: Localização das Praças.

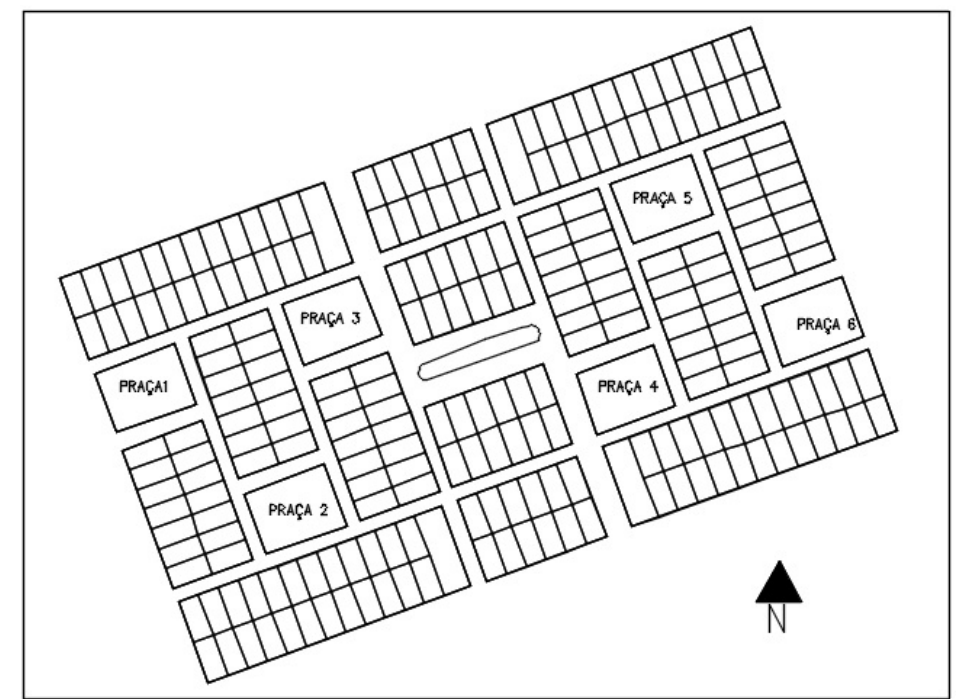

Fonte: Autores, 2017.

Para o conhecimento dos aspectos dos equipamentos instalados nas praças do Conjunto do Café, foram realizados levantamentos e atribuídos conceitos segundo uma avaliação qualitativa de cada um. Porém a avaliação qualitativa tem em si certa subjetividade, portanto, os resultados são dependentes do avaliador.

As praças do bairro são praças projetadas, por esse motivo, todas elas têm o mesmo padrão em sua forma geométrica e equipamentos, apresentando formato retangular, modificando apenas o desenho interno, sendo que as praças 1, 4, 5 e 6 tem seu desenho interno com caminhos a partir das extremidades formando uma área central circular. (Figura 3, 4, 5 e 6).

Figura 3: Praça do Café 1.
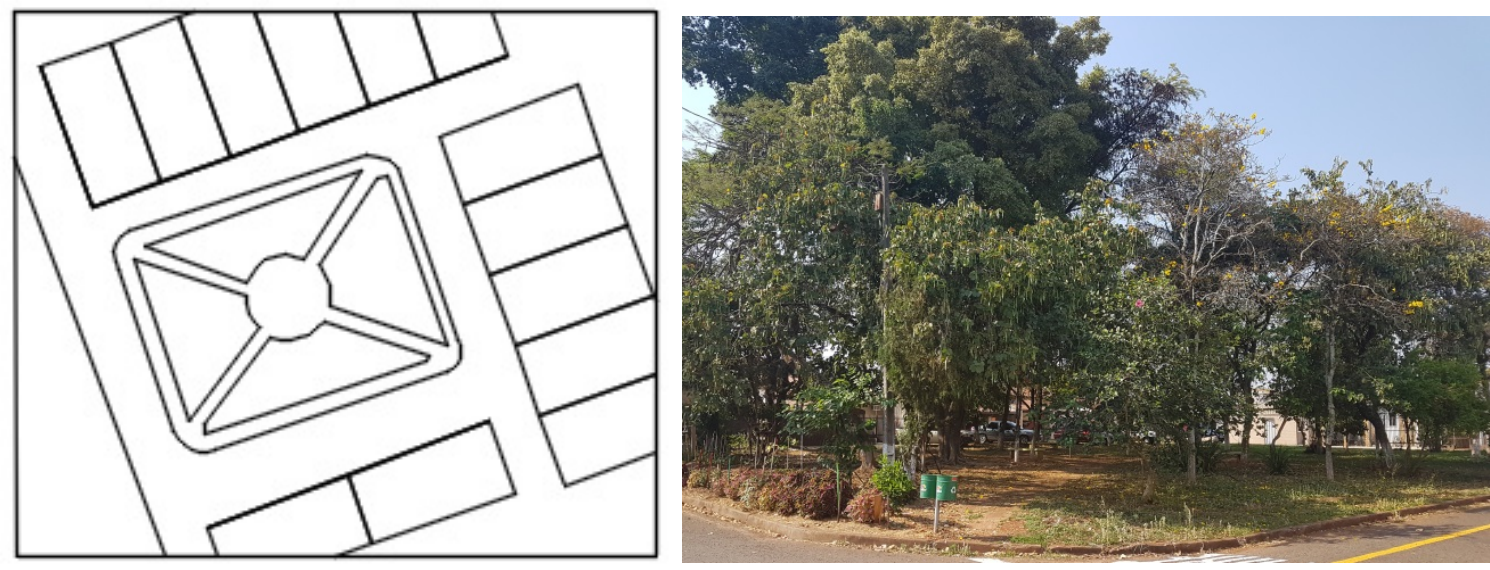

Fonte: Autores, 2017. 


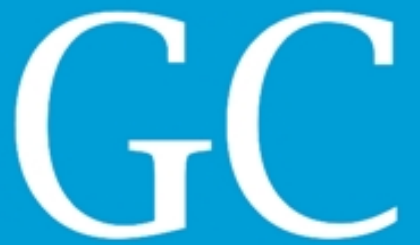

Revista Nacional de

Figura 4: Praça do Café 4.
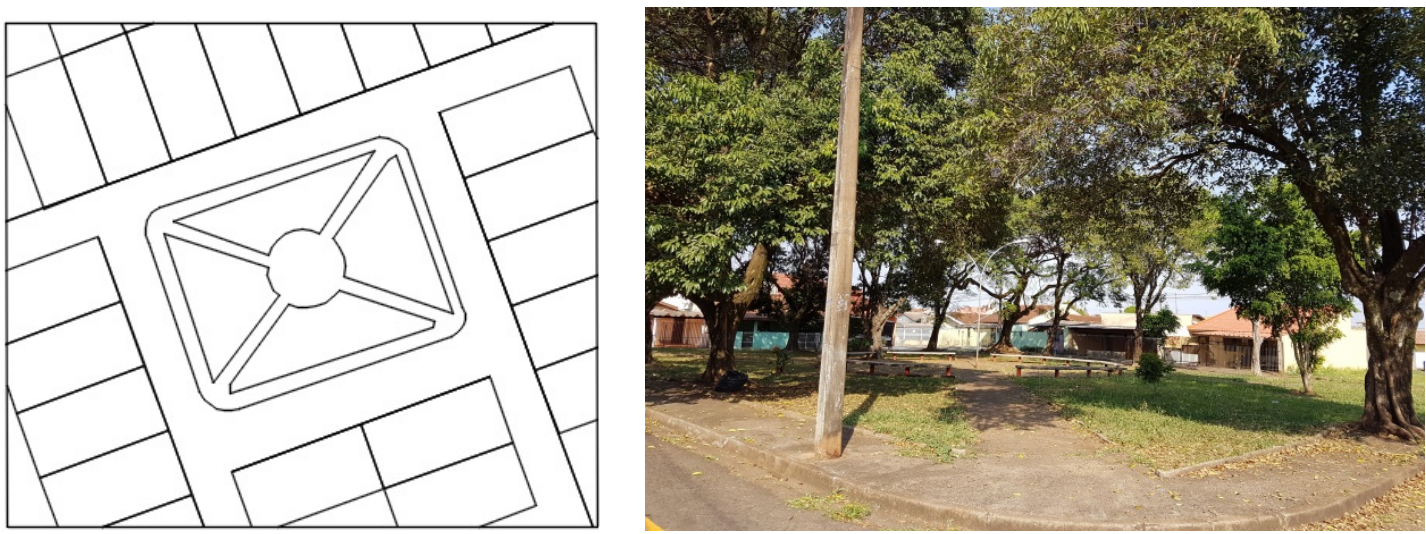

Fonte: Autores, 2017

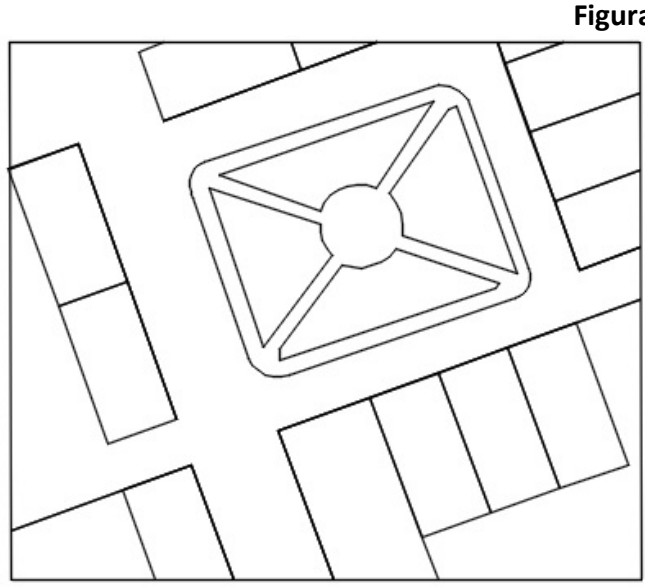

Figura 5: Praça do Café 5.

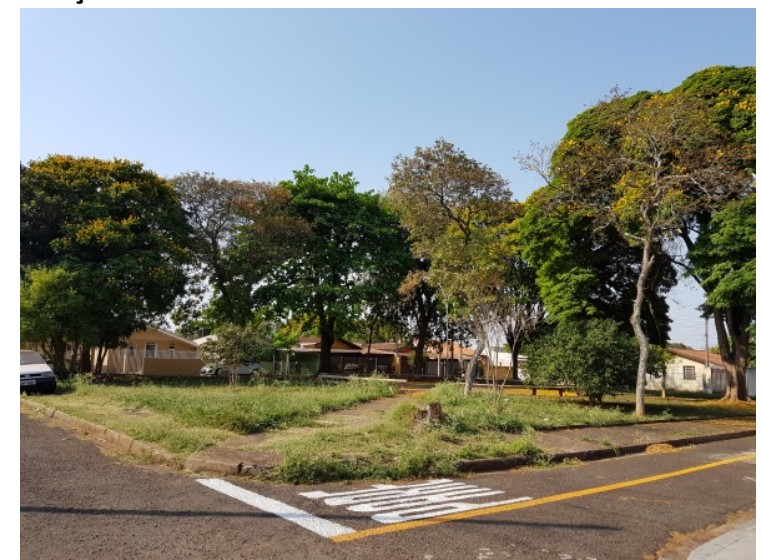

Fonte: Autores, 2017.

Figura 6: Praça do Café 6.
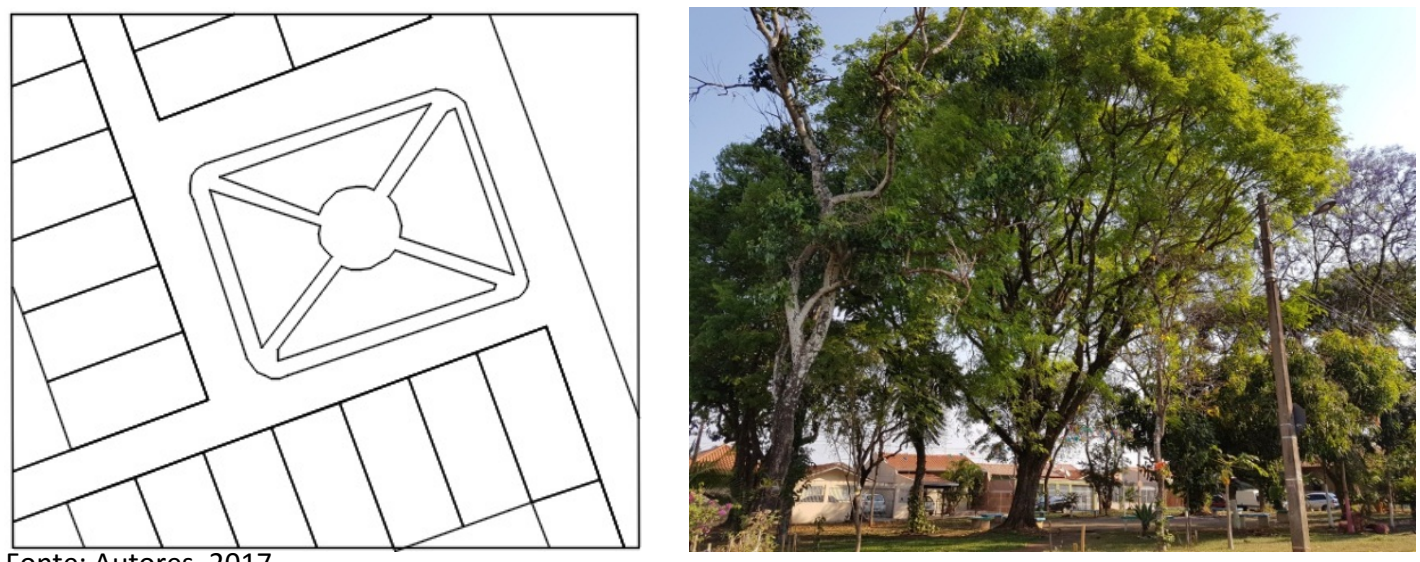
As praças 2 e 3 tem seu desenho interno em forma de retângulos, formando os jardins, e seus caminhos estão localizados no centro da praça. Na área central da praça também forma um espaço livre onde estão dispostos os bancos.

Figura 7: Praça do Café 2.
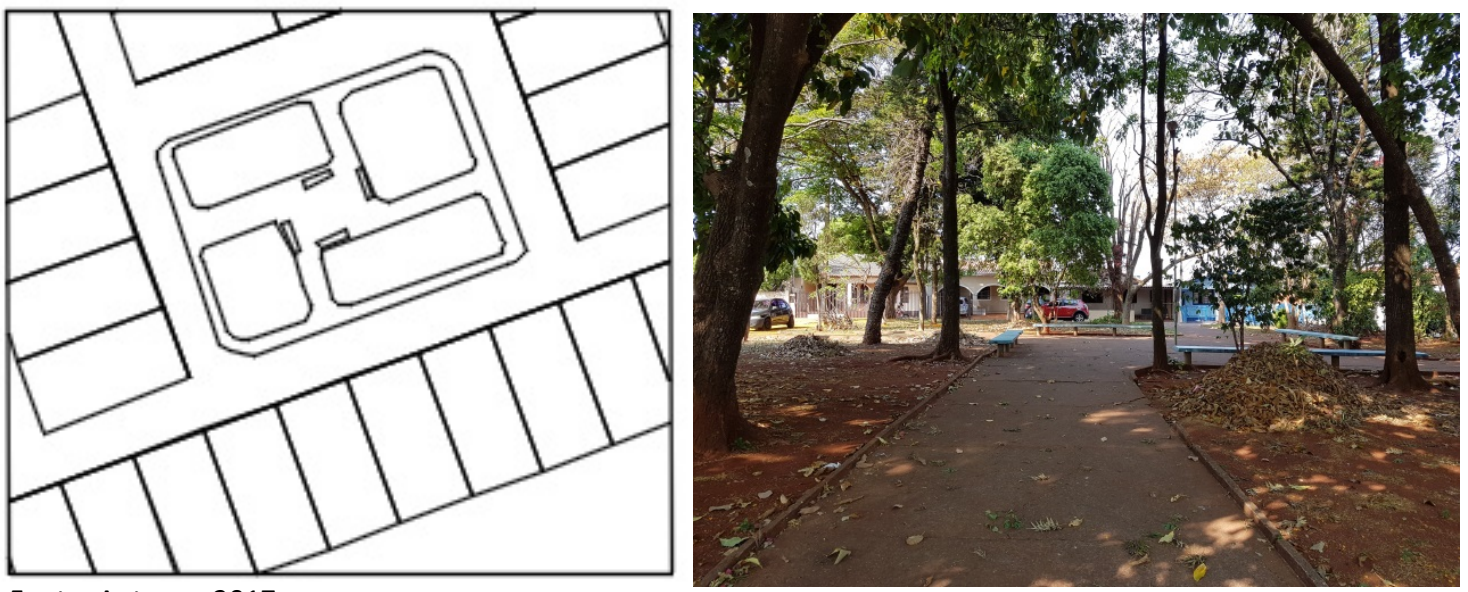

Fonte: Autores, 2017.

Figura 8: Praça do Café 3.
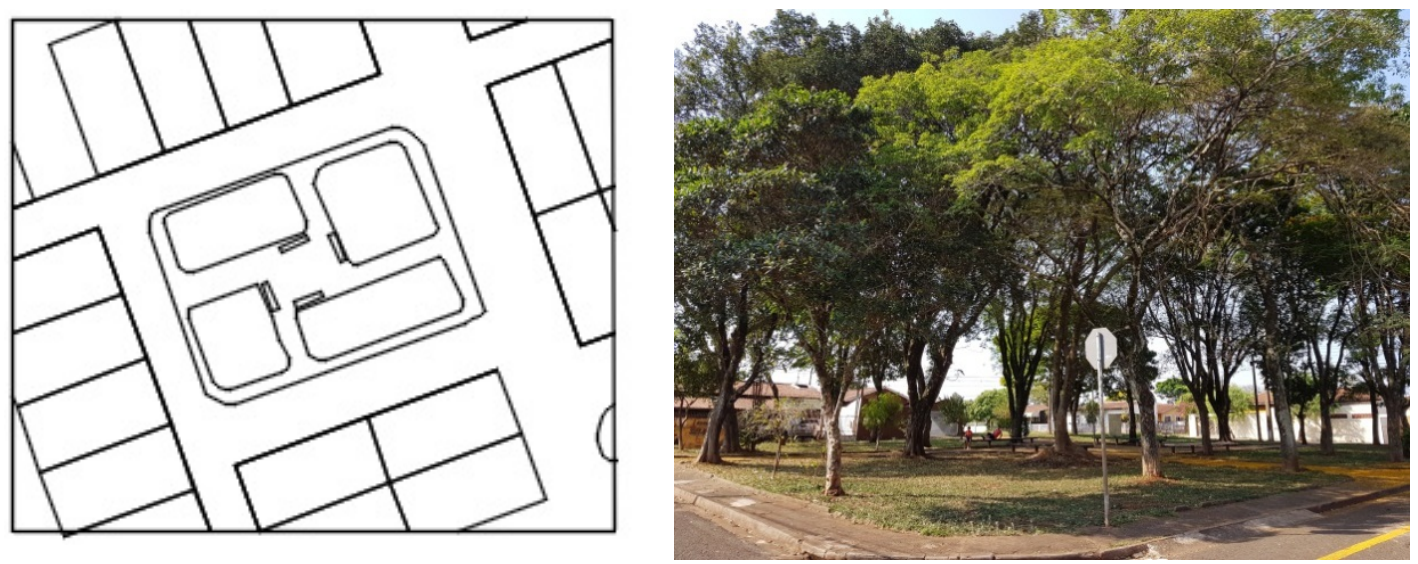

Fonte: Autores, 2017.

$\mathrm{Na}$ área central de todas as praças, estão localizados os bancos, sendo 4 bancos de concreto e 1 poste de iluminação alta também de ferro. Somente a praça 6 que fica na divisa do bairro possui 10 bancos, também em concreto. Os caminhos de todas as praças são de concreto, não foi constatado diferença de padrão. Em relação às lixeiras, apenas na Praça 1 possui esse mobiliário, são 5 lixeiras confeccionadas em ferro, destas 4 estão dispostas nas extremidades e uma na área central.

Quanto aos pontos de ônibus, este item só foi encontrado na Praça 6. Esta praça está na divisa de bairro, sendo que a via ao lado deste espaço é uma via coletora onde circula o transporte público. Nas outras praças, a ausência deste elemento se deve pela dificuldade em que os o transporte público teria ao trafegar, principalmente pelo fato das vias internas serem muito estreitas. 


\section{Revista Nacional de}

Na análise quantitativa, conforme a metodologia adotada foi feitas avaliações in loco e estas são apresentadas na tabela 1.

Tabela 1: Avaliação Qualitativa da Infraestrutura das Praças.

\begin{tabular}{ccccccc}
\hline Equipamento & Praça 1 & Praça 2 & Praça 3 & Praça 4 & Praça 5 & Praça 6 \\
\hline Bancos & 2,5 & 2,5 & 2,5 & 2,5 & 2,5 & 2,5 \\
Poste de Luz & 1,0 & 1,5 & 1,3 & 1,5 & 1,5 & 2,0 \\
Lixeira & 1,5 & & & & & \\
Ponto de Ônibus & & & & & & 3,5 \\
Caminhos & 0,5 & 1,0 & 1,0 & 1,5 & 0,5 & 2,0 \\
Vegetação & 3,5 & 3,5 & 3,5 & 3,5 & 3,8 & 3,8 \\
Conforto & 4,0 & 4,0 & 4,0 & 4,0 & 4,0 & 4,0 \\
\hline Ambiental & & & & & & \\
\hline
\end{tabular}

Fonte: Autores, 2017.

Em todas as praças, dentre os elementos que compõe a infraestrutura, destaca-se o ponto de ônibus localizado na Praça 6 por estar em ótimas condições de uso e do outro lado, como pontos ruins das praças, estão os caminhos das Praças 1 e 5, (Figura 9) por estarem com buracos, partes quebradas e irregulares, dificultando o deslocamento de pessoas com necessidades especiais. Em relação a vegetação, todas as plantas existentes no local estão em estado geral em ótimas condições sendo que a manutenção (podas) não foi constada em nenhuma das espécies.

$\mathrm{Na}$ análise do conforto ambiental, no quesito conforto acústico foi considerado ótimo, pelo fato das vias serem de apenas 3 metros de largura, o fluxo de carros no interior do bairro é somente de moradores e visitantes. No conforto térmico e sombreamento, também podem ser classificados como ótimo, pois as árvores, em sua maioria de grande porte produzem uma área de sombra no espaço. Em relação a impermeabilização do solo, somente as áreas de caminhos contempla uma área impermeável, que, por ser de concreto, resulta em uma área gramada maior. 
Figura 9: Caminhos Praça 1 e 5.
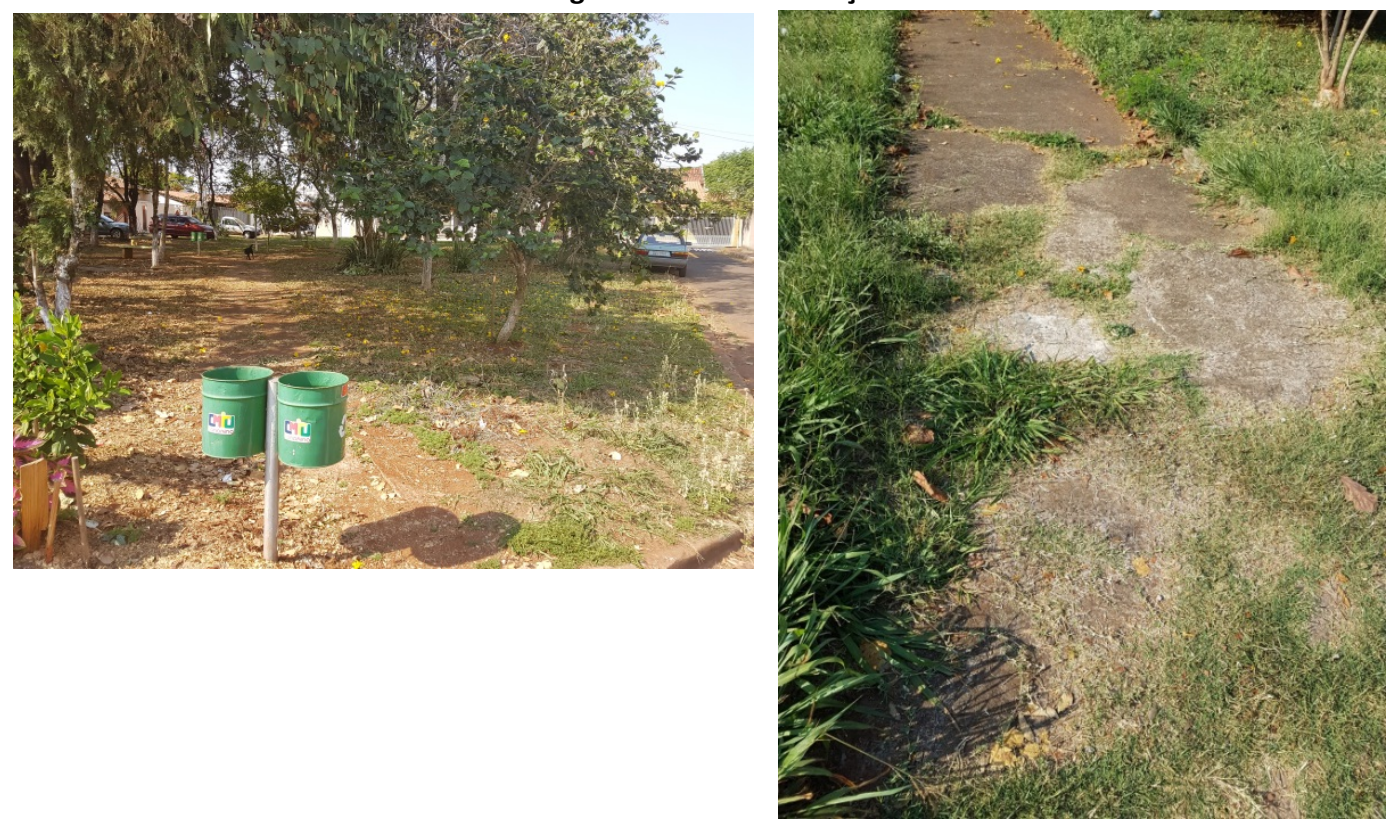

Fonte: Autores, 2017.

A arborização nas praças contribui para garantir a qualidade de vida e promover benefícios para a população, por isso à importância desse elemento no meio urbano. As praças, por ser um ambiente livre de construções, permitem o emprego de espécies com potencial paisagístico e de sombreamento. Diante a importância da vegetação na urbe, foi realizado o levantamento para conhecer as espécies existentes nas 6 praças analisadas. Na análise quantitativa da vegetação, foi encontrado em todas as praças o mesmo tipo de árvores, diferenciando apenas em quantidade. 
Tabela 1: Lista de espécies encontradas nas 6 Praças do Café.

\begin{tabular}{|c|c|c|c|c|}
\hline Família & Espécie & Frequência (\%) & Nome vulgar & Origem \\
\hline Araucariaceae & $\begin{array}{c}\text { Auracaria angustifolia } \\
\text { Bertol Kuntze }\end{array}$ & 1,16 & $\begin{array}{l}\text { Pinheiro do } \\
\text { Paraná }\end{array}$ & Nativa \\
\hline Araucariaceae & Auracaria heterophylla & 1,16 & $\begin{array}{l}\text { Pinheiro de } \\
\text { Norfolk }\end{array}$ & Exótica \\
\hline \multirow{2}{*}{ Bignoniaceae } & $\begin{array}{c}\text { Handroanthus } \\
\text { chrysotrichus (Mart. ex } \\
\text { DC.) Mattos }\end{array}$ & 20,93 & Ipê amarelo & Nativa \\
\hline & $\begin{array}{c}\text { Handroanthus } \\
\text { heptaphyllus (Vell.) } \\
\text { Mattos }\end{array}$ & 4,65 & Ipê roxo & Nativa \\
\hline Fabaceae & $\begin{array}{c}\text { Bauhinia Forficata } \\
\text { var. latifolia Benth }\end{array}$ & 8,13 & Pata de Vaca & Nativa \\
\hline Fabaceae & $\begin{array}{c}\text { Poincianella pluviosa var. } \\
\text { peltophoroides (Benth.) } \\
\text { L.P.Queiroz }\end{array}$ & 20,93 & Sibipiruna & Nativa \\
\hline Fabaceae & Tamarindus indica $L$. & 1,16 & Tamarindus & Exótica \\
\hline Oleaceae & $\begin{array}{c}\text { Ligustrum lucidum } \\
\text { W. T. Aiton }\end{array}$ & 20,93 & Ligustro & Exótica \\
\hline Malvaceae & $\begin{array}{c}\text { Hibiscus rosa-sinensis } \\
L .\end{array}$ & 11,62 & Hibisco Rosa & Exótica \\
\hline Moraceae & $\begin{array}{c}\text { Artocarpus } \\
\text { heterophyllus Lam. }\end{array}$ & 1,16 & Jaqueira & Exótica \\
\hline Moraceae & Ficus benjamina $L$. & 1,16 & $\begin{array}{l}\text { Figueira- } \\
\text { Benjamim }\end{array}$ & Exótica \\
\hline Nyctaginaceae & $\begin{array}{c}\text { Bougainvillea glabra } \\
\text { Choisy }\end{array}$ & 2,36 & Primavera & Nativa \\
\hline Lauraceae & $\begin{array}{c}\text { Persea americana } \\
\text { Mill. }\end{array}$ & 4,65 & Abacateiro & Exótica \\
\hline TOTAL & & $100 \%$ & & \\
\hline
\end{tabular}

Fonte: Autores, 2017.

No estudo quantitativo das árvores é possível perceber que a espécie com maior frequência de utilização é a Poincianella pluviosa Benth. Flish (Sibipiruna) com 18 unidades ou seja 20,93\%. A Sibipiruna pode ser encontrada frequentemente nas praças brasileiras, é o que assevera o estudo de Gomes (2016) no estudo das praças de Campo Mourão, onde foi encontrado 32,6\% dessa espécie na praça São José e 32,2\% na praça Bento Munhoz. A Ligustrum lucidum W. T. Aiton (Ligustro) também é uma das árvores mais encontradas nas praças, esta consta portaria n.59/2015 do IAP como exótica invasora, seguido pelo Handroanthus chrysotrichus Mattos ambos com 20,93\% de frequência. Apesar da frequência de mais de $20 \%$ de apenas 3 tipos de árvores, as praças possuem uma diversidade de árvores, pois como informa Moll (1987) a frequência por espécies não deve ser maior que $10 \%$ do total de árvores. Milano e Dalcin (2000) concluem que para um bom planejamento de arborização urbana, as especies arbóreas não deveriam ser superior a $15 \%$. 
Um dos aspectos positivos da arborização das praças é a a predominância de $58,16 \%$ de espécies nativas e $41,84 \%$ de espécies exóticas. Corforme afirma Ziller (2001) no planejamento arbóreo de um local as plantas nativas devem ser prioridade, pois as espécies exóticas podem causar diversos danos ao ambiente, como a perda de biodiversidade, modificações nos ciclos e características naturais, alteração fisionômica da paisagem natural e pode haver consequências econômicas. Das 6 praças analisadas, a praça que contém mais indivíduo arbóreo é a praça 3 com 18 árvores sendo a Sibipiruna a espécie com maior quantidade, seguida pela praça 1, com 17 unidades, com a predominância é a Bauhinia Forficata var. latifolia Bent. Em seguida está a praça 6 com 16 unidades sendo o Handroanthus chrysotrichus a espécie que mais tem indivíduos, 7 unidades. A praça 2 possui 14 indivíduos tendo o Persea americana Mill. e o Ligustrum lucidum com a maior quantidade. Na praça 4 existe 13 árvores, sendo a espécie Ligustrum lucidum a que predomina, são 9 unidades só neste local. E por último a praça 5 com a menor quantidade de indivíduos arbóreo, com apenas 8 , com a predominância do Handroanthus chrysotrichu.

\section{CONCLUSÃO}

As praças são elementos essencias no espaço de uma cidade, elas desempenham diferentes funções, tai como: estética, lazer e ambiental. Porém a falta de interesse do poder público nesses locais, faz com que esses espaços, principalmente nos bairros da periferia, serjam carentes de uma melhor infraestrutura e manutenção, seja da vegetação ou dos equipamentos. No caso das praças analisadas, apesar de não ter uma estrutura completa, a infraestrutura existente estão em boas condições de uso, destaca-se apenas negativamente os caminhos de duas praças que necessitam de reparos, principalmente no quesito da mobilidade, pois eles estão irregulares, o que dificulta a passagem de alguém com dificuldade de locomoção. Em relação a vegetação existente, todas os 86 indivíduos existentes estão em ótimas condições, não aparesentam visualmente nenhuma patologia. Nas praças a vegetação ainda contribui para o conforto ambiental local, como elas já são árvores formadas, o sombreamento produzido por elas auxiliam na qualidade ambiental do local. Além disso, compete ao poder público realizer a manutenção desses locais, levando em consideração as funções desses espaços, seja a socialização e o lazer.

\section{REFERÊNCIAS BIBLIOGRÁFICAS}

AYOUB, T. Conjuntos Habitacionais e Espaços Livres: Correlações Socioespaciais e Orientações Projetuais. Dissertação de Mestrado, UEL, 2014.

BOVO, M. C., ANDRADE, T. B. Produção do Espaço histórico-cultural de Campo Mourão (PR) Brasil: um estudo de suas praças centrais. Revista Formação Online, v. 19, n.1, p. 3-24, 2012.

A significação, o uso e a representatividade social dos espaço públicos: o caso das praças São José e Getúlio Vargas em Campo Mourão/PR. Anais do V Encontro de Produção Científica e Tecnológica, 2010.

DE ANGELIS, Bruno L. D.; CASTRO, Rosana M.; ANGELIS NETO, Generoso. Metodologia para levantamento e cadastramento, diagnóstico e avaliação de praças no Brasil. Engenharia Civil, UM. n.20, p. 57-70, 2004. 


\section{Revista Nacional de}

FAVOLE, P. La plaza en la arquitectura contemporânea. Barcelona: Gustavo Gilli, 1995.

FONT, M. A praça em Movimento: processos de transformações morfológicas e funcionais no Brasil do século XX. Dissertação de Mestrado - USP, 2003.

GOMES, D. C. Análise das praças centrais de Campo Mourão, Paraná, na configuração urbana. Dissertação de Mestrado. UEM, 2016.

INSTITUTO BRASILEIRO DE GEOGRAFIA E CIÊNCIA $\quad-\quad$ IBGE. Disponível em http://cidades.ibge.gov.br/xtras/perfil.php?codmun=411370 acesso em 19/09/2017.

INSTITUTO AMBIENTAL DO PARANÁ - IAP Resolução 59/2015. Disponível em: http://iap.pr.gov.br/arquivos/File/Lista invasoras PR corrigida set 2015.pdf

LAMAS, J. M. R. G. Morfologia urbana e desenho da cidade. Fundação Calouste Gulbenkian, 1993.

LONDRINA. Dados demográficos. Disponível em:

http://www.londrina.pr.gov.br/index.php?option=com_content\&view=article\&id=40:dados-geograficos\&catid=5:acidade\&Itemid=58 . Acesso em 19/09/2017.

MARX, M. Cidade Brasileira. Melhoramentos. Editora Universidade de São Paulo, 1980.

MENEGUETTI, K. S. Cidade Jardim, Cidade Sustentável. A Estrutura ecológic urbana e a cidade de Maringá. Maringá: EDUEM, 2009.

MILANO, M. DALCIN, E. Arborização de vias públicas. Rio de Janeiro: Light, 2000.

MOLL, G. Improving the health of the urban Forest. American Forests, Washington, v. 93, n. 11/12, p. 61-64, 1987.

ROBBA, F.; MACEDO, S. S. Praças brasileiras. São Paulo: Edusp/ Imprensa Oficial do Estado, 2010. (Coleção Quapá).

SALDANHA, N. O jardim e a praça: ensaio sobre o privado e o lado público da vida social e histórica. Ciência \& Trópico, América do Norte, 11, mai. 2011.

SILVA, G. C.; LOPES, W. G. R.; LOPES, J. B. Evolução, mudanças de uso e apropriação de espaços públicos em áreas centrais urbanas. Ambiente Construído, vol. 11, n. 3, 2011.

SILVEIRA, G.; BARROS, M. V. F. Perfil geoambiental de praças: região norte na cidade de Londrina - PR. Semina: Ciências Exatas e tecnológicas. V. 22, p. 63-71, 2001.

YOKOO, S. C., CHIES, C. O papel das praças públicas: estudo de caso da praça Raposo Tavares na cidade de Maringá. IV EPCT Encontro de Produção Científica e Tecnológica, 2009.

ZILLER, S. R. A Estepe Gramíneo-Lenhosa no segundo planalto do Paraná: diagnóstico ambiental com enfoque à contaminação biológica. 2000. 268 f. Tese Doutorado. Universidade Federal do Paraná, Curitiba, 2000. 